\title{
Die Septuaginta und das frühe Christentum - The Septuagint and Christian Origins
}

\author{
Hrsg. v. Thomas S. Caulley u. Hermann Lichtenberger
}

Die Septuaginta und das frühe Christentum

The Septuagint and Christian Origins

Herausgegeben von T CAULLEY und HERMANN LICHTENBERGER

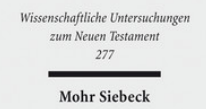

2011. IX, 451 Seiten. WUNT I 277

ISBN 978-3-16-151776-1

DOI 10.1628/978-3-16-151776-1

eBook PDF 159,00€

ISBN 978-3-16-150561-4

Leinen $159,00 €$
Die Septuaginta stellt die älteste Übersetzung der Hebräischen Bibel ins Griechische dar. In den Beiträgen dieses Bandes wird die Übersetzung der Septuaginta in den Rahmen der Übersetzung anderer religiöser Texte der Antike gestellt und die spezifische Weise der Übersetzung in den einzelnen Schriften und zu zentralen Begriffen erfaßt. Von grundlegender Bedeutung wurde die Septuaginta für das entstehende Christentum und seine Literatur. In welcher Weise im Neuen Testament die Septuaginta aufgenommen wurde, wird differenziert in einer ganzen Reihe von Untersuchungen entfaltet. Schließlich wird der Blick über die neutestamentliche Literatur in die Patristik hinein ausgeweitet.

Mit Beiträgen von:

Eberhard Bons, Thomas Scott Caulley, Athanasios Despotis, Reinhard Feldmeier, Ron Heine, Carl Holladay, Gudrun Holtz, Wolfgang Kraus, Stefan Krauter, Armin Lange, Hermann Lichtenberger, Ulrike Mittmann, David Moessner, Heinz-Dieter Neef, Anna Maria Schwemer, Folker Siegert, Hermann Spieckermann, Loren Stuckenbruck, Emanuel Tov, J. Cornelis de Vos

Thomas S. Caulley Keine aktuellen Daten verfügbar.

Hermann Lichtenberger Geboren 1943; Studium der Evangelischen Theologie und der Semitischen Sprachen in Erlangen und Heidelberg; 1976 Promotion; 1986 Habilitation; 1993-2010 Professor für Neues Testament und antikes Judentum in Tübingen.

Jetzt bestellen:

https://mohrsiebeck.com/buch/die-septuaginta-und-das-fruehe-christentum-the-septuagint-and-christian-origins9783161517761 ?no cache $=1$

order@mohrsiebeck.com

Telefon: +49 (0)7071-923-17

Telefax: +49 (0)7071-51104 